\title{
Editorial
}

\section{Statistics in practical decision making}

\author{
Stan Lipovetsky \\ Co-Editor-in-Chief
}

This issue is devoted to statistics applied to decision making problems. The issue begins from consideration of methodological possibilities to construct regressions with meaningful and interpretable coefficients for individual predictors and shares of their importance. Ewa Nowakowska explores properties of the so-called Shapley value regression developed for adjusting regression coefficients with multicollinearity among the predictors and estimating their importance. D. Liakhovitski, Y. Bryukhov, and M. Conklin compare the approaches of random forests and relative weights of the predictors in regressions under various scenarios. Together with $\mathrm{M}$. Conklin we investigate further features of Shapley value regression and its predicting abilities.

The next several works present statistical methods for solving different practical decision making problems. Dr. B. Vilge considers possibilities of regression predictions for chemically active materials by physical and chemical characteristics measured by non-destructive testing. Prof. J. Subramani describes how proper and meaningful decisions should be taken in modern manufacturing process control. Profs. S. Saxena, H.P. Singh, O.K. Gupta, and K.S. Rao share their experience on Bayesian assessment of failure and repair times for systems and components helping to reliability engineers to take correct decisions. And Prof. E. Demidenko shows how to choose the optimal portfolio to reach the investors' financial goals.

And continuing already established tradition of giving topic quotations, here are some more of them on decision making.

"Refuse the evil, and choose the good." Bible, Isaiah 7:15

"It is your own convictions which compels you; that is, choice compels choice." Epictetus

"Nothing is more difficult, and therefore more precious, than to be able to decide." Napoleon Bonaparte

“Once you make a decision, the universe conspires to make it happen.” Ralph Waldo Emerson

"The secret of success in life is for a man to be ready for his opportunity when it comes." Benjamin Disraeli

"When you have to make a choice and don't make it, that in itself is a choice." William James

"In a moment of decision, the best thing you can do is the right thing to do. The worst thing you can do is nothing." Theodore Roosevelt

"When making a decision of minor importance, I have always found it advantageous to consider all the pros and cons. In vital matters, however, such as the choice of a mate or a profession, the decision should come from the unconscious, from somewhere within ourselves. In the important decisions of personal life, we should be governed, I think, by the deep inner needs of our nature." Sigmund Freud

"To get anywhere, or even to live a long time, a man has to guess, and guess right, over and over again, without enough data for a logical answer." Robert Heinlein 
"You and I are essentially infinite choice-makers. In every moment of our existence, we are in that field of all possibilities where we have access to an infinity of choices." Deepak Chopra

"You can choose where to spend eternity." Thomas Saaty, The Thinking Man's New Millennium Joke Book, Part I, 55

"It is the theory that decides what can be observed." Albert Einstein

"Everything is foreseen, yet freedom of choice is granted." The Wisdom of the Fathers, Heritage Press, New York, 1960, 78 